OPEN ACCESS

Edited by:

Min Yue,

Zhejiang University, China

Reviewed by:

Veronica Risco-Castillo,

INRA École Nationale Vétérinaire

d'Alfort (ENVA), France

David Arranz-Solis,

University of California, Davis,

United States

Luiz Miguel Pereira,

University of São Paulo, Brazil

Guangxu Ma

Zhejiang University, China

*Correspondence:

Xichen Zhang

xczhang@jlu.edu.cn

Pengtao Gong

gongpt@jlu.edu.cn

tThese authors have contributed equally to this work

Specialty section: This article was submitted to Veterinary Infectious Diseases, a section of the journal Frontiers in Veterinary Science

Received: 04 December 2020 Accepted: 11 January 2021

Published: 19 February 2021

Citation:

Dong J, Zhang N, Zhao P, Li J, Cao L, Wang $X$, Li X, Yang J, Zhang $X$ and Gong P (2021) Disruption of Dense Granular Protein 2 (GRA2) Decreases the Virulence of Neospora caninum

Front. Vet. Sci. 8:634612. doi: 10.3389/fvets.2021.634612

\section{Disruption of Dense Granular Protein 2 (GRA2) Decreases the Virulence of Neospora caninum}

\author{
Jingquan Dong ${ }^{1,2+}$, Nan Zhang ${ }^{1 \dagger}$, Panpan Zhao ${ }^{1,2+}$, Jianhua Li $^{1}$, Lili Cao ${ }^{1,3}$, Xiaocen Wang ${ }^{1}$, \\ Xin $\mathrm{Li}^{1}$, Ju Yang ${ }^{1}$, Xichen Zhang ${ }^{1 *}$ and Pengtao Gong ${ }^{1 *}$ \\ ${ }^{1}$ Key Laboratory of Zoonosis, College of Veterinary Medicine, Jilin University, Changchun, China, ${ }^{2}$ Jiangsu Key Laboratory of \\ Marine Biological Resources and Environment, Jiangsu Key Laboratory of Marine Pharmaceutical Compound Screening, \\ Co-Innovation Center of Jiangsu Marine Bio-industry Technology, Jiangsu Ocean University, Lianyungang, China, \\ ${ }^{3}$ Department of Parasite, Jilin Academy of Animal Husbandry and Veterinary Medicine, Changchun, China
}

Neospora caninum causes abortions in cattle and nervous system dysfunction in dogs. Dense granular proteins (GRAs) play important roles in virulence; however, studies on NcGRA functions are limited. In the present study, multiple methods, including site-directed mutagenesis; CRISPR/Cas9 gene editing; Western blotting; quantitative polymerase chain reaction; confocal microscopy; plaque, invasion, egress, and replication assays; animal assays of survival rate and parasite burden; and hematoxylin-eosin staining, were used to characterize the NcGRA2 protein, construct an NcGRA2 gene disruption ( $\triangle \mathrm{NcGRA2}$ ) strain, and explore its virulence in vivo and vitro. The results showed that NcGRA2 shared $31.31 \%$ homology with TgGRA2 and was colocalized with NcGRA6 at the posterior end of tachyzoites and the intravacuolar network of parasitophorous vacuoles (PVs). Cell fractionation analysis showed that NcGRA2 behaved as a transmembrane and membrane-coupled protein. The $\triangle$ NcGRA2 strain was constructed by coelectroporation of the NcGRA2-targeting CRISPR plasmid (pNc-SAG1-Cas9:U6-SgGRA2) and DHFR-TS DNA donor and verified the protein, genome, and transcriptional levels and by immunofluorescence localization analysis. The in vitro virulence results showed that the $\triangle$ NcGRA2 strain displayed smaller plaques, similar invasion and egress abilities, and slower intracellular growth. The in vivo virulence results showed a prolonged survival time, lower parasite burden, and mild histopathological changes. Overall, the present study indicates that NcGRA2, as a dense granular protein, forms the intravacuolar network structure of PVs and weakens N. caninum virulence by slowing proliferation. These data highlight the roles of NcGRA2 and provide a foundation for research on other protein functions in N. caninum.

Keywords: Neospora caninum, CRISPR, dense granules protein 2, intravacuolar network, immunofluorescence

\section{INTRODUCTION}

Neospora caninum, an obligate intracellular protozoan pathogen, belongs to the phylum Apicomplexa and leads to neosporosis with clinical manifestations of reproductive failure in bovines and nervous system dysfunction in dogs (1-7). It has been reported that the total annual loss in the cattle industry caused by $N$. caninum infection worldwide is as high as US $\$ 43.08$ billion 
to US $\$ 320.98$ billion $(8,9)$. As a country with a large amount of animal husbandry, China has begun to pay increasing attention to $N$. caninum infections. Currently, no commercial treatment with $N$. caninum is available. Pretreatment and control of neosporosis are mainly by sulfonamides or attenuated vaccines; however, these drugs have relatively large negative effects, and resistance to them forms easily, leading to incomplete elimination of $N$. caninum $(10,11)$. Thus, it is urgent to look for new targets against neosporosis.

$N$. caninum replicates in a specialized membranous organelle known as the parasitophorous vacuole (PV), which is formed by parasites inside host cells after invasion, separates parasites from the cytoplasm, and resists host cell acidification and lysosomal zymohydrolysis (12). The intravacuolar network (IVN) inside the PV is composed of highly curved membrane tubules and shares the functions of ingesting nutrients from hosts and linking parasites and the PV membrane (PVM). Similar to other apicomplexan parasites, $N$. caninum discharges proteins produced in secretory organelles, and these are micronemes (MICs), rhoptries (ROPs) and dense granules (GRAs) during periods of invasion into host cells, adhesion to the surface of cell membranes, or survival and development in the PV (13). MICs are not only involved in parasite attachment to hosts, but also play important roles in invasion. ROPs are restricted to the bulb of organelles and secreted while/after the formation of the PVs to manipulate the host cell. RONs are from the neck of ROPs and play roles in parasite attachment and invasion into hosts (14). Most of the information about the roles of MICs, ROPs, and GRAs comes from Toxoplasma gondii, which is closely related to $N$. caninum. GRAs are involved in remodeling and maintaining the environment of the PV and play key roles in the replication of T. gondii (15-18).

The IVN is the most important structure within the PV in T. gondii. Apart from the aforementioned nutrient absorption and establishment connection with PVM, the IVN can also help T. gondii to divide in order to optimize their synchronous division (19-21) and to deliver secreted proteins to construct the PVM $(22,23)$ and is involved in virulence by accelerating ROP release into PVM and then maintain PVM stabilization $(22,24)$. Furthermore, TgGRA2 is regarded as a typical GRA candidate involved in IVN biogenesis. It is embedded in the IVN through the structures of two amphipathic alpha helices (AAHs) (21). Deletion of the TgGRA2 gene completely disrupts the IVN structure, and complementation assays of TgGRA2 proteins further showed that not only the AAH structure but also the N-terminal hydrophilic domain were important factors in the formation of $\operatorname{IVN}(21,25)$. Despite these clues verifying the importance of TgGRA2, GRA2 in N. caninum was first identified in 2000; its location in bradyzoites was explored in 2004, and its immune protection was evaluated in a mouse model using recombinant GRA2 protein in 2008; however, its role in $N$. caninum virulence is still unknown (26-28).

In N. caninum, studies on NcGRA functions are limited. Here, we characterized an $N$. caninum GRA protein, NcGRA2. Using the $N$. caninum-specific CRISPR/Cas9 system, we generated an NcGRA2 disruption strain ( $\triangle \mathrm{NcGRA2}$ ) based on the Nc1 strain of $N$. caninum; verified the $\triangle$ NcGRA2 strain at the protein, genome, and transcriptional levels; and, through localization analysis, and further explored its pathogenicity in vivo and in vitro. These data highlight the roles of NcGRA2 in N. caninum virulence.

\section{MATERIALS AND METHODS}

\section{Ethics Statement}

All animal experiments have received approval for research ethics from the Animal Welfare and Research Ethics Committee of Jilin University, and the certificate number is pzpx20190929065. Five-week-old BALB/C female mice and 6-month-old NZW male rabbits were fed sterile water and food and housed in 12-h light-dark cycle feeding cages.

\section{Cells and Parasite Strains}

Bovine kidney epithelial (MDBK) cells and human skin fibroblast (HFF) cells (ATCC, USA) were cultured in Dulbecco modified eagle medium (DMEM; Biological Industries, Israel) supplemented with $10 \%$ fetal bovine serum (FBS; Biological Industries, Israel), $100 \mathrm{U} / \mathrm{mL}$ penicillin, and $100 \mu \mathrm{g} / \mathrm{mL}$ streptomycin (Biological Industries, Israel) under conditions of $37^{\circ} \mathrm{C}$ and $5 \% \mathrm{CO}_{2}$. MDBK cell line shares fast growth rate; in contrast, HFF cell line shares relative slow growth rate. MDBK cells can be passaged every 2 days in a ratio of 1:3 and HFF cells can be passaged every 5-7 days in a ratio of 1:2. For N. caninum tachyzoites preparation, it is better to use MDBK cell line to obtain enough tachyzoites with a shorter period. For plaque assays used in the construction of the $\triangle \mathrm{NcGRA} 2$ strain and virulence in vitro, HFF cell line is a better choice for its slow growth rate, makes single tachyzoite form observed plaques, and increases the success probability of single tachyzoite plaque screening. Meanwhile, considering the necessary of HFF cell line for plaque assays, other virulence studies in vitro were also used in the HFF cell line.

To rapidly obtain the Nc-1 strain of $N$. caninum tachyzoites, tachyzoites were grown in fast-growing MDBK cells and purified as described previously (29). In brief, $N$. caninum tachyzoites were collected when $80 \%$ of the host cells were lysed and passed through a 27 -gauge needle. Then, the tachyzoites were isolated from host cell debris and further purified with $40 \%$ (vol/vol) Percoll (GE Healthcare, Uppsala, Sweden) by centrifugation at $2,500 \times g$ for $10 \mathrm{~min}$. After washing with phosphate-buffered saline (PBS), the concentrations of tachyzoites were determined with a hemocytometer.

\section{Preparation of a Rabbit Polyclonal Antibody Against NcGRA2}

The NcGRA2 gene was amplified from tachyzoite cDNA with specific primers (forward: 5'-ATGGAATTCGCCGATTTT TCTGGCAGGGGAA-3'; reverse: $5^{\prime}$-GTACTCGAGTTAATT GACTTCAGCTTCT-3') using Phusion ${ }^{\circledR}$ High-Fidelity DNA Polymerase (NEB, Inc., USA) according to the manufacturer's instructions. The underlined nucleotides in the forward and reverse primer are the restriction enzyme cutting sites of EcoRI and XhoI, respectively. The purified NcGRA2 polymerase chain reaction (PCR) products and extracted pGEX-4T-1 
TABLE 1 | Primer sequences used for generation of the $\triangle$ NcGRA2 strain.

\begin{tabular}{ll}
\hline Primer name & Sequence $\left(5^{\prime}-3^{\prime}\right)$ \\
\hline sgNcGRA2-F & GGTTATTCCGGATATCCCCGGTITAGAGCTAGAAATAGC \\
sgNcGRA2-R & AAACAACAATGTCCCTIGGCA \\
KO $^{\mathrm{C}}$-NcGRA2-F & ATGTTCACGGGGAAACGTTGGATATAAGCTTACTCGTCGCC \\
& AGCAGT \\
KO $^{\mathrm{C}}$-NcGRA2-R & CTATIITCCTCCCCGCCGTITCGGTCGGAATTAGGTCGG \\
& AAAAGT
\end{tabular}

${ }^{a}$ F represented forward.

${ }^{b} R$ represented reverse.

${ }^{c} K O$ represented knockout.

plasmid were treated with EcoRI and XhoI enzymes and ligated together with T4 DNA ligase (TaKaRa, Dalian). The mixtures were transformed into Trans1T1 competent cells (TranGen, Beijing), and the recombinant plasmid pGEX-4T-NcGRA2 was identified through sequencing. The positive pGEX-4T-NcGRA2 plasmid was transformed into BL21 competent cells (TranGen, Beijing), followed by induction of expression. The recombinant pGEX-4T-NcGRA2 protein (rNcGRA2) was analyzed using sodium dodecyl sulfate-polyacrylamide gel electrophoresis (SDS-PAGE). The soluble rNcGRA2 protein was purified using GSTrap FF purification columns (GE Healthcare Bio-Sciences, USA). NZW rabbits were immunized subcutaneously with $500 \mathrm{ng}$ of rNcGRA2 emulsified with equal volume of Freund's complete adjuvant (Sigma, USA). The rabbits were boosted with $300 \mathrm{ng}$ of rNcGRA2 emulsified with equal volume of Freund's incomplete adjuvant two times with a 14-day interval. Polyclonal antibodies against rNcGRA2 were generated after 14 days since the last injection.

\section{Plasmid Construction of the NcGRA2 CRISPR Gene Editing Vectors}

An $N$. caninum gene editing plasmid, pNc-SAG1::CAS9U6::sgUPRT (Supplementary Figure 1), which contained the $N$. caninum U6 promoter, Cas9-monomeric enhanced green fluorescent protein (Cas9-mEGFP), 5' UTR and 3' UTR of the $N$. caninum SAG1 gene, sgRNA sequence of UPRT, ampicillin resistance gene (AmpR), origin of replication (ori), and $\mathrm{f} 1$ ori, was used as a template to construct the NcGRA2 CRISPR gene editing vectors (29). Specific sgRNA sequences were searched via E-CRISP online software (http://www.e-crisp.org/E-CRISP/ designcrispr.html), and primer sequences for sgNcGRA2 were designed, which are listed in Table 1. The primer sgNcGRA2$F$ contained an extra 20 bp of guide RNA sequence for NcGRA2 and 20 bp of nucleotide sequence adjacent to the guide RNA in pNc-SAG1::CAS9-U6::sgUPRT. To substitute sgUPRT with sgNcGRA2, site-directed mutagenesis was carried out using a Q5 ${ }^{\circledR}$ Site-Directed Mutagenesis Kit (NEB, USA) according to the manufacturer's instructions. The amplification products were verified using sequencing methods by Comate Bioscience Company.

\section{Construction of the $\Delta$ NcGRA2 Strain}

The DHFR-TS DNA donor was amplified using the pNcDHFR plasmid as a template. After purification, $2 \mu \mathrm{g}$ of DHFR-TS DNA donor, $6 \mu \mathrm{g}$ of pNc-SAG1::CAS9-U6::sgGRA2 plasmid, and $300 \mu \mathrm{L}$ of Nc-1 strain $\left[4 \times 10^{7}\right.$ tachyzoites $/ \mathrm{mL}$ dissolved in Cytomix (Thermo Fisher, USA)] were fully mixed and then electroporated under conditions of $1,500 \mathrm{~V} / 25 \mu \mathrm{F} / 50 \Omega$. Next, the transfection mixture was inoculated into MDBK cells and cultured under conditions of $37^{\circ} \mathrm{C}$ and $5 \% \mathrm{CO}_{2}$. Tachyzoites were collected when $80 \%$ of the host cells were lysed, and the $N$. caninum $\triangle$ NcGRA2 strain was screened as follows. First, $2 \mathrm{~mL}$ of purified tachyzoites was inoculated into slow-growing HFF cells and cultivated for $7 \mathrm{~h}$. Then, $1 \mu \mathrm{M}$ pyrimethamine was added into the cultures, which were incubated for 5-7 days until half of the tachyzoites had egressed (30). After purification, tachyzoites were again inoculated into HFF cells and screened under pyrimethamine. Next, a total of 80-120 tachyzoites were suspended in $10 \mathrm{~mL}$ of DMEM supplemented with $10 \%$ FBS and inoculated into a 96-well plate at $100 \mu \mathrm{L}$ per well to make tachyzoites replication (none, one or more tachyzoites per well). After culturing for 5 days, the plate was observed under an optical microscope; wells with no or multiple plaques were discarded, and wells with a single plaque were continuously cultured for another 3 days. Then, the single tachyzoites in wells with a single plaque were transferred to HFF cells cultured in 12-well plates. The screened $\triangle \mathrm{NcGRA} 2$ strain was then assessed using Western blotting detection, PCR amplification, real-time quantitative PCR (qPCR) analysis, and immunofluorescence observation.

\section{Protein Sample Preparation, SDS-PAGE, and Western Blotting}

Analysis of the major forms of the NcGRA2 protein and assessment of the $\triangle \mathrm{NcGRA} 2$ strain at the protein expression level were both carried out using Western blotting assays. For NcGRA2 protein form analysis, infected MDBK cells were resuspended in PBS, and supernatants were collected after elimination of parasites and cell debris by needles and centrifugation at $2,500 \times g$ for $10 \mathrm{~min}$. Next, cell fractionation was used to divide the samples into soluble [high-speed supernatant (HSS)] and membrane-associated [high-speed pellet (HSP)] fractions by ultracentrifugation at 100,000 $\times g$ for $2 \mathrm{~h}$. HSPs were dissolved in $50 \mu \mathrm{L}$ of $50 \mathrm{mM}$ Tris buffer $(\mathrm{pH}$ 8.0) supplemented with $1 \mathrm{mM}$ PMSF (Solarbio, China) protease inhibitor. The HSS was precipitated with acetone (31), and the pellets were suspended in an equal volume of Tris buffer used in the HSP sample. To further separate proteins, the HSP solution was sonicated $(60 \mathrm{H} / 30 \mathrm{~s})$ on ice for $30 \mathrm{~min}$ and stored in a denaturant of $10 \%$ Triton X-114. Finally, the samples were collected and ultracentrifuged at $100,000 \times g$ for $2 \mathrm{~h}$ to separate the pellets and supernatants. The obtained detergent phase (D) and aqueous phase (A) were individually precipitated with acetone and dissolved in an equal volume of Tris buffer (32). The prepared samples $(10 \mu \mathrm{L})$ were used for SDS-PAGE. For assessment of the $\triangle \mathrm{NcGRA} 2$ strain, total proteins were extracted from the Nc-1 and $\triangle$ NcGRA2 strains using RIPA lysis buffer containing $1 \mathrm{mM}$ PMSF protease inhibitor. Concentrations of 
these obtained proteins were measured using a BCA Protein Assay Kit (Thermo Scientific, USA), and $20 \mu \mathrm{g}$ of protein samples was used for SDS-PAGE. Protein samples were mixed with $5 \times$ SDS-PAGE sample loading buffer (Beyotime, China), boiled for $10 \mathrm{~min}$, subjected into $12 \%$ SDS-PAGE, and then electrophoresed in Tris-glycine-SDS buffer under conditions of $80 \mathrm{~V}$ for $1 \mathrm{~h}$ and then $120 \mathrm{~V}$ for $40 \mathrm{~min}$. For Western blotting analysis, the targeted proteins were transferred onto $0.45 \mu \mathrm{m}$ PVDF membranes (Millipore, USA) under conditions of $200 \mathrm{~mA}$ for $1 \mathrm{~h}$. The membranes were blocked in 5\% skim milk at $4{ }^{\circ} \mathrm{C}$ overnight and then incubated with a specific rabbit polyclonal antibody against NcGRA2, a specific rabbit polyclonal antibody against NcGRA7, or a mouse polyclonal antibody against NcSRS22A (prepared in our laboratory) at a dilution of 1:200 under conditions of $37^{\circ} \mathrm{C}$ for $1 \mathrm{~h}$. NcGRA7 antibody was used to verify the purity of fractions. NcSRS22A is a putative surface antigen and used as a control in N. caninum. After washing three times (5 min per wash) with PBST, the membranes were then incubated with secondary antibodies of either goat anti-rabbit immunoglobulin $\mathrm{G}(\mathrm{IgG})(\mathrm{H}+\mathrm{L})$ or goat anti-mouse IgG $(\mathrm{H}+\mathrm{L})$ (Earthox, USA) at a dilution of 1:5,000 under conditions of $37^{\circ} \mathrm{C}$ for $1 \mathrm{~h}$. Finally, the membranes were washed three times again with PBST and incubated with ECL chemiluminescence reagents (Thermo Scientific, USA) for $5 \mathrm{~min}$. The bands were viewed on a Western Blot Imaging System (Clinx, China).

\section{PCR Amplification}

Amplification of the DHFR-TS DNA donor or assessment of $\triangle$ NcGRA2 was conducted through PCR assays with Phusion ${ }^{\circledR}$ High-Fidelity DNA Polymerase according to the manufacturer's instructions. For DHFR-TS DNA donor amplification, specific primers for KO-NcGRA2 were designed and are listed in Table 1. The primer set for KO-NcGRA2 contained $23 \mathrm{bp}$ of homologous sequences with the two ends of the protospacer adjacent motif in the $N$. caninum genome at the $5^{\prime}$ end and $25 \mathrm{bp}$ of specific DHFR-TS sequences at the $3^{\prime}$ end. The aim of introduction with homologous sequences was to make homology-directed repair (HDR) and non-homologous end joining (NHEJ) simultaneously function and finally improve the recombinant efficiency. Errors in annealing may probably be due to incompletely matched at the $3^{\prime}$ end, and unmatched sequences were introduced at the $5^{\prime}$ end in the present study. For $\triangle$ NcGRA2 assessment, specific primers targeting the $5^{\prime}$ UTR and $3^{\prime}$ UTR of the N. caninum SAG1 gene (P1 and P2) or DHFR-TS gene (P3 and P4) were designed and are listed in Table 2. The reaction system contained $200 \mathrm{ng}$ plasmid template of $\mathrm{pNcDHFR}$ or $1 \mu \mathrm{g}$ genome DNA template of $\triangle \mathrm{NcGRA} 2$ or Nc-1 strains, $0.2 \mu \mathrm{L}$ of Phusion DNA Polymerase, $4 \mu \mathrm{L}$ of $5 \times$ Phusion HF Buffer, $0.4 \mu \mathrm{L}$ of dNTPs $(10 \mu \mathrm{M}), 1$ $\mu \mathrm{L}$ of forward and reverse primers $(10 \mu \mathrm{M})$, and nuclease-free water to a final volume of $20 \mu \mathrm{L}$. The amplification program was set as follows: predenaturation at $98^{\circ} \mathrm{C}$ for $30 \mathrm{~s}$, followed by 35 amplification cycles of denaturation at $98^{\circ} \mathrm{C}$ for $10 \mathrm{~s}$, annealing at $55^{\circ} \mathrm{C}$ for $30 \mathrm{~s}$, and extension at $72^{\circ} \mathrm{C}$ for $1 \mathrm{~kb} / \mathrm{min}$, with a final extension at $72^{\circ} \mathrm{C}$ for $10 \mathrm{~min}$. The amplification products were detected on a $1.5 \%$ agarose gel.
TABLE 2 | Primer sequences used for verification of the $\triangle$ NcGRA2 strain.

\begin{tabular}{ll}
\hline Primer name & Sequence $\left(\mathbf{5}^{\prime} \mathbf{-} \mathbf{3}^{\prime} \mathbf{)}\right.$ \\
\hline P1 & ACAAAGCCCAGGACATCCGAAAA \\
P2 & TCCCACAAGTAACTGTTTGACTATT \\
P3 & GAAGCACACGTTCAGAGACCA \\
P4 & TAGCTCCAGTGTGTCTGTTCCT \\
NcGRA2-F & CAATGGACAGCCGGTTGGCA \\
NcGRA2-R & TCCGACCTTCGCAGTAAACT \\
Actin-F & TGAGAGAGGATACGGTT \\
Actin-R & GGCAGCGGAAGCGCTCGTT \\
\hline
\end{tabular}

${ }^{a} F$ represents forward.

${ }^{b} R$ represents reverse.

\section{Real-Time qPCR}

To assess the $\triangle \mathrm{NcGRA} 2$ strain, $\mathrm{qPCR}$ assays were carried out to measure the GRA2 gene transcription level as previously described (28). Briefly, RNA was extracted from $\triangle$ NcGRA2 or Nc-1 strains using TRIzol reagent (Invitrogen, USA) according to the manufacturer's instructions. The parameters of concentration and purity were evaluated on a Nanodrop ND-2000 apparatus (Thermo Scientific, USA). Then, $1 \mu \mathrm{g}$ of total RNA was used for cDNA synthesis with the PrimeScript ${ }^{\mathrm{TM}}$ RT Reagent Kit (TaKaRa, China). qPCR assays were used for quantification of the GRA2 mRNA expression levels with FastStart Universal SYBR Green Master Mix (Roche, Germany) on a qTOWER 2.0 (Analytikjena, Germany) instrument. A total volume mixture of $20 \mu \mathrm{L}$ contained $10 \mu \mathrm{L}$ of $2 \times$ SYBR qPCR mix, $1 \mu \mathrm{L}$ of NcGRA2 or actin primer $(10 \mu \mathrm{M}$, Table 2$), 1 \mu \mathrm{L}$ of diluted cDNA samples, and nuclease-free water. qPCR was performed as follows: predenaturation at $95^{\circ} \mathrm{C}$ for $10 \mathrm{~min}$, followed by 40 amplification cycles of denaturation at $95^{\circ} \mathrm{C}$ for $10 \mathrm{~s}$ and annealing and extension at $60^{\circ} \mathrm{C}$ for $30 \mathrm{~s}$. The fluorescence signal was read at the extension stage after each cycle, and the melting curve was set as the default. The mRNA fold change was measured by calculating $2^{-\Delta \Delta \mathrm{Ct}}$, where $\Delta \mathrm{Ct}$ represents the $\mathrm{Ct}$ (target gene) - Ct (actin), and $\Delta \Delta \mathrm{Ct}$ represents the $\Delta \mathrm{Ct}$ (sample) $-\Delta \mathrm{Ct}$ (control).

\section{Confocal Microscopy}

Localization of NcGRA2 protein in the Nc-1 strain of N. caninum tachyzoites or infected MDBK cells and assessment of the protein expression levels in the $\triangle$ NcGRA2 strain were both performed through immunofluorescence assays. Purified Nc-1 tachyzoites were added to coverslips pretreated with $0.1 \mathrm{mg} / \mathrm{mL}$ poly-Llysine (Sigma, St. Louis, MO, USA) and allowed to stand for $30 \mathrm{~min}$. To clearly locate the distribution of NcGRA2 protein in PVs, the cells previously coated on coverslips were infected with tachyzoites (parasite-host ratio, MOI $=3$ ) and incubated for $48 \mathrm{~h}$. The tachyzoites or infected cells were then fixed in a $4 \%$ paraformaldehyde solution at room temperature for $20 \mathrm{~min}$ and permeabilized in $0.5 \%$ Triton-X-100. After washing three times with PBST, the samples were blocked in 5\% bovine serum albumin (BSA) at $4^{\circ} \mathrm{C}$ for $12 \mathrm{~h}$. For the localization analysis of the NcGRA2 protein, tachyzoites or infected cells were 
coincubated with a specific rabbit polyclonal antibody against NcGRA2 and a rat polyclonal antibody against NcGRA6 at a dilution of 1:200 under conditions of $37^{\circ} \mathrm{C}$ for $2 \mathrm{~h}$. Then, cells or tachyzoites were washed three times with PBST and again coincubated with labeled secondary detection antibodies of fluorescein isothiocyanate (FITC)-conjugated goat anti-rabbit $\operatorname{IgG}(\mathrm{H}+\mathrm{L})$ and $\mathrm{Cy} 3$-conjugated goat anti-rat $\operatorname{IgG}(\mathrm{H}+\mathrm{L})$ (Earthox, USA) at a dilution of $1: 400$ under conditions of $37^{\circ} \mathrm{C}$ for $1 \mathrm{~h}$. To assess whether NcGRA2 was successfully disrupted in the $\triangle \mathrm{NcGRA} 2$ strain, MDBK cells were infected either with the Nc-1 strain or $\triangle$ NcGRA2 strain and incubated for shorter time of $24 \mathrm{~h}$. After fixation, the cells were both coincubated with a specific rabbit polyclonal antibody against NcGRA2 and a mouse polyclonal antibody against NcSRS22A at a dilution of $1: 200$ under conditions of $37^{\circ} \mathrm{C}$ for $2 \mathrm{~h}$. Subsequently, the samples were again coincubated with labeled secondary detection antibodies of FITC-conjugated goat anti-mouse IgG $(\mathrm{H}+\mathrm{L})$ and Cy3-conjugated goat anti-rabbit IgG $(\mathrm{H}+\mathrm{L})$ (Earthox, USA) at a dilution of $1: 400$ under conditions of $37^{\circ} \mathrm{C}$ for $1 \mathrm{~h}$. Nuclei in the cells and tachyzoites were stained with DAPI (Thermo, USA) at room temperature for $10 \mathrm{~min}$ at a final concentration of $300 \mathrm{nM}$. After washing five times with PBST, tachyzoites or infected cells were analyzed on an FV1000 laser scanning confocal microscopy (LSCM, Olympus, Japan).

\section{Plaque Assay}

Plaque assays were performed as previously described (33). Parasites were seeded onto HFF cells previously coated on sixwell plates to a final concentration of 80-120 tachyzoites per well and incubated under conditions of $37^{\circ} \mathrm{C}$ and $5 \% \mathrm{CO}_{2}$ for 7 days. Then, the culturing medium was discarded, and the cells were washed three times with PBS and fixed in $4 \%$ paraformaldehyde at room temperature for $20 \mathrm{~min}$. After washing three times with PBS, the cells were further stained for $15 \mathrm{~min}$ with $1 \%$ crystal violet, which was removed with deionized water. The dried plaques were scanned with a light microscope (Olympus, Japan), and the area was calculated as described previously (34).

\section{Invasion Assay}

Invasion assays were performed in HFF cells coated on coverslips in six-well plates. Freshly purified parasites were seeded onto HFF monolayers to a final concentration of $1 \times 10^{5}$ tachyzoites per well and incubated for 20,40, and $60 \mathrm{~min}$. After fixation, the cells were blocked with $5 \% \mathrm{BSA}$ at $37^{\circ} \mathrm{C}$ for $1 \mathrm{~h}$ and then incubated with a primary antibody against $\mathrm{NcSRS} 22 \mathrm{~A}$ at $37^{\circ} \mathrm{C}$ for $2 \mathrm{~h}$. After washing three times with PBST, the cells were further incubated with a secondary antibody of FITC-conjugated goat anti-mouse IgG $(\mathrm{H}+\mathrm{L})$. Next, the cells were permeabilized with $0.2 \%$ Triton $\mathrm{X}-100$ at $37^{\circ} \mathrm{C}$ for $0.5 \mathrm{~h}$ and again blocked in BSA at $37^{\circ} \mathrm{C}$ for $1 \mathrm{~h}$. The cells were incubated sequentially with a specific antibody against NcSRS22A and a secondary detection antibody of Cy3-conjugated goat anti-mouse IgG $(\mathrm{H}+\mathrm{L})$, and labeled parasites were observed on the LSCM. The invasion percentage was calculated as \{(number of Cy3-labeled parasites - number of FITC-labeled parasites)/number of Cy3-labeled parasites $\} \times 100 \%$.

\section{Egress Assay}

Similar to T. gondii, N. caninum tachyzoites replicate in the PV after invasion into host cells and then egress out and enter uninfected cells $(35,36)$. The egress assays were performed as previously described (29). A total of $1 \times 10^{5}$ tachyzoites were inoculated onto HFF cells coated on coverslips in six-well plates under conditions of $37^{\circ} \mathrm{C}$ and $5 \% \mathrm{CO}_{2}$ for $1 \mathrm{~h}$, and then the extracellular parasites were discarded by washing three times with sterilized PBS. HFF cells were cultured in fresh medium for $48 \mathrm{~h}$. Next, egress was stimulated by adding the $\mathrm{Ca}^{2+}$ ionophore A23187 (Sigma, USA) to a final concentration of $3 \mu \mathrm{M}$ for $3 \mathrm{~min}$, and the dimethyl sulfoxide (DMSO)-treated group was used as a control. Immunofluorescence assays were performed using mouse polyclonal antibodies against NcSRS22A and CY3conjugated goat anti-mouse IgG $(\mathrm{H}+\mathrm{L})$ as described above. The disrupted or integrated PV was determined by the distribution of labeled tachyzoites where gathered tachyzoites were in the integrated PV, whereas diffused tachyzoites were found around the disrupted PV. The egress percentage was determined by counting the mean disrupted PV number from 100 randomly selected vacuoles.

\section{Replication Assay}

Purified parasites $\left(1 \times 10^{6}\right.$ tachyzoites per well $)$ were inoculated onto HFF cells coated on coverslips in six-well plates for $4 \mathrm{~h}$, and the supernatants were replaced with fresh medium. Then, cells were collected at different time points of $6,12,24$, and $36 \mathrm{~h}$; fixed in 4\% paraformaldehyde; and used for immunofluorescence assays with antibodies against NcSRS22A and FITC-conjugated goat anti-mouse IgG $(\mathrm{H}+\mathrm{L})$ as outlined above. The replication ability was determined by observing the numbers of labeled parasites in 100 randomly selected vacuoles.

\section{Virulence in Laboratory Mice}

Acute infection models and non-lethal infections were both established to evaluate virulence in vivo. Five-week-old female $\mathrm{BALB} / \mathrm{C}$ mice were divided into three groups to explore the difference in virulence between the Nc-1 strain and $\triangle \mathrm{NcGRA} 2$ strain. For the acute infection models, $2 \times 10^{7}$ tachyzoites were injected intraperitoneally (i.p.) into mice (five mice per group) and monitored for 40 days. Sterilized PBS was used as a control. Mice that lost their ability to drink water or eat food for more than $24 \mathrm{~h}$ and lost $20 \%$ body weight were humanely euthanized by cervical dislocation after subcutaneous injection of atropine $(0.02 \mathrm{mg} / \mathrm{kg})$, and the survival time was recorded (33).

To explore the effects of $N$. caninum on host tissues, a nonlethal dose of tachyzoites $\left(2 \times 10^{6}\right.$ per mouse $)$ was injected i.p. into mice (nine mice per group), and heart, liver, spleen, lung, kidney, and brain tissues were isolated after euthanasia at 3, 7, and 15 days postinfection (dpi). Tissues in the NC group and $\mathrm{Nc}-1$ group were isolated at $15 \mathrm{dpi}$. The parasite burden was determined by measuring the Nc5 gene contents using an absolute qPCR assay with tissue genomic DNA as a template (37). The histopathological changes in the isolated tissues were determined by hematoxylin-eosin (HE) assay as previously described (29). Briefly, fresh tissues were washed with $0.9 \% \mathrm{NaCl}$, cut into patches, and immediately fixed in $4 \%$ 
paraformaldehyde. After dehydration with ethanol and dimethyl benzene, the tissues were embedded in paraffin, sectioned into 5$\mu \mathrm{m}$-thick sections, and then mounted on slides. After removal of paraffin and sequential treatment with hematoxylin solution, acid alcohol, and ammonia solution, the slides were stained with eosin solution, dehydrated, and sealed. Histopathological changes were viewed under a light microscope.

\section{Statistical Analysis}

Data are expressed as the mean $\pm \mathrm{SD}$ and were analyzed by the non-parametric Mann-Whitney $U$-test using SPSS 18.0 (SPSS Inc., USA). Kaplan-Meier survival curves were analyzed using the log-rank (Mantel-Cox) test. Graphs were generated in GraphPad Prism 7.00 (GraphPad Inc., La Jolla, CA, USA). All experiments were performed three times with three technical replicates. Differences between the Nc-1 strain and $\triangle$ NcGRA2 strain were considered statistically significant at ${ }^{*} p<0.05$ or ${ }^{* *} p$ $<0.01$, and no significance was denoted as n.s.

\section{RESULTS}

\section{Characterization of an $\mathbf{N}$. caninum Dense Granule Protein NcGRA2}

A bioinformatics prediction of NcGRA2 (NCLIV_045650) showed that the signal peptides were located at amino acids 1-23, and no potential transmembrane regions existed (Supplementary Figure 2). Specific primers were designed to amplify the NcGRA2 gene from cDNA using PCR, and a target band of $600 \mathrm{bp}$ was obtained. Then, the NcGRA2 gene was cloned into the pGEX-4T-1 vector, and the positive recombinant plasmid pGEX-NcGRA2 was transformed into Rosetta (DE3). After induction of expression, a $35-\mathrm{kD}$ a protein was obtained. For further characterization of NcGRA2, a rabbit polyclonal antibody against NcGRA2 was also generated.

For exploration of the localization of the NcGRA2 protein, immunofluorescence assays were carried out both in the parasites and in infected MDBK cells. As shown in Figure 1A, NcGRA2 could colocalize with NcGRA6 at the posterior end of tachyzoites. For the infected cells, similar to the location of NcGRA6, NcGRA2 was mainly distributed in the IVN structure of PV (38). To further analyze the existing forms of the NcGRA2 protein in the PV, cell fractionation analysis was performed. The purity of fractions was verified using NcGRA7. As shown in Figure 1B, NcGRA2 existed in both the HSS and HSP; moreover, the amounts in the HSS and HSP were approximately the same. This indicated that secreted GRA2 existed in soluble and membraneassociated forms. To further explore the relationship between NcGRA2 and membranes, HSP was then dissolved in Triton X-114 denaturant. After ultracentrifugation, the results showed that HSP could exist in the detergent phase and aqueous phase. These data indicated that NcGRA2 behaved as a transmembrane protein and a membrane-coupled protein.

\section{Successful Construction of the $\triangle$ NcGRA2 Strain}

We designed a CRISPR/Cas9 system with sitedirected mutagenesis technology for the $N$. caninum
NcGRA2 gene, designated pNc-SAG1::CAS9-U6::sgGRA2 (Supplementary Figure 3), based on the $N$. caninum gene editing vector of pNc-SAG1::Cas9-U6::sgUPRT. The fulllength DHFR-TS cassette with homologous sequences of the NcGRA2 protospacer adjacent motif was obtained by PCR assay with templates of the $N$. caninum selectable marker pNc-DHFR plasmid. To construct the $\triangle$ NcGRA2 strain, the pNc-SAG1::CAS9-U6::sgGRA2 and the DHFR-TS cassette were coelectroporated into Nc-1 tachyzoites, and the $\triangle \mathrm{NcGRA} 2$ strain was isolated from single clone culture strains after screening under pyrimethamine pressure.

For further assessment of the $\triangle \mathrm{NcGRA} 2$ strain, the NcGRA2 protein expression level, genome level, and transcriptional level, coupled with the localization of the NcGRA2 protein, were measured. As shown in Figures 2A,B, NcGRA2 protein expression was evaluated in the $\triangle \mathrm{NcGRA} 2$ strain and $\mathrm{Nc}-1$ strain, and the surface antigen protein NcSRS22A was used as a control. Western blotting analysis indicated that NcSRS22A existed in both strains; however, the NcGRA2 protein existed only in the Nc-1 strain and was absent in the $\triangle$ NcGRA2 strain. These results verified that the NcGRA2 protein was disrupted in the $\triangle \mathrm{NcGRA} 2$ strain.

Next, we determined the NcGRA2 gene at the genome level by PCR amplification. Three PCR products, named PCR1, PCR2, and PCR3, were amplified with primers P1/P3, P2/P4, and P1/P2. As expected, products of PCR1 and PCR2 were both generated only in the $\triangle \mathrm{NcGRA} 2$ strain, which successfully inserted the DHFR-TS cassette; in contrast, products of 500 and 1,400 bp were absent in the Nc-1 strain. The product size of PCR3 in the NcGRA2 disruption strain was 4,000 bp larger than that in the Nc-1 strain (Figure 2C). After purification of PCR amplification products and sequencing, the results further verified that fulllength DHFR-TS cassette had been successfully inserted into the Nc-1 strain accompanied by the NcGRA2 gene disruption.

NcGRA2 gene disruption was also evaluated at the transcriptional level. cDNA from the Nc-1 strain and NcGRA2 disruption strain was prepared, and qPCR assays were carried out. Ct values of the NcGRA2 gene and the housekeeping gene actin were measured, and the mRNA fold change was calculated by $2^{-\Delta \Delta C t}$. As shown in Figure 2D, the NcGRA2 gene expression level in the $\triangle$ NcGRA2 strain group was downregulated in comparison with the control group of the Nc-1 strain. The residual relative mRNA levels of NcGRA2 calculated by $2^{-\Delta \Delta C t}$ were probably due to the background signals when the target gene was in low concentrations. The results of transcriptional level verified that the NcGRA2 gene was successfully disrupted.

For localization analysis of the NcGRA2 protein, immunofluorescence assays were performed. Infected MDBK cells were coincubated with specific antibodies against NcSRS22A and NcGRA2 and then labeled with different detection antibodies. As shown in Figure 2E, the blue signals represented DAPI-stained nuclei, the green signals represented FITCconjugated goat anti-mouse IgG $(\mathrm{H}+\mathrm{L})$-stained NcSRS22A protein, and the red signals indicated $\mathrm{Cy} 3$-conjugated goat anti-rabbit IgG $(\mathrm{H}+\mathrm{L})$-stained NcGRA2 protein. Both green and red signals existed in the Nc-1 strain; however, the red signal 
$\mathbf{A}$
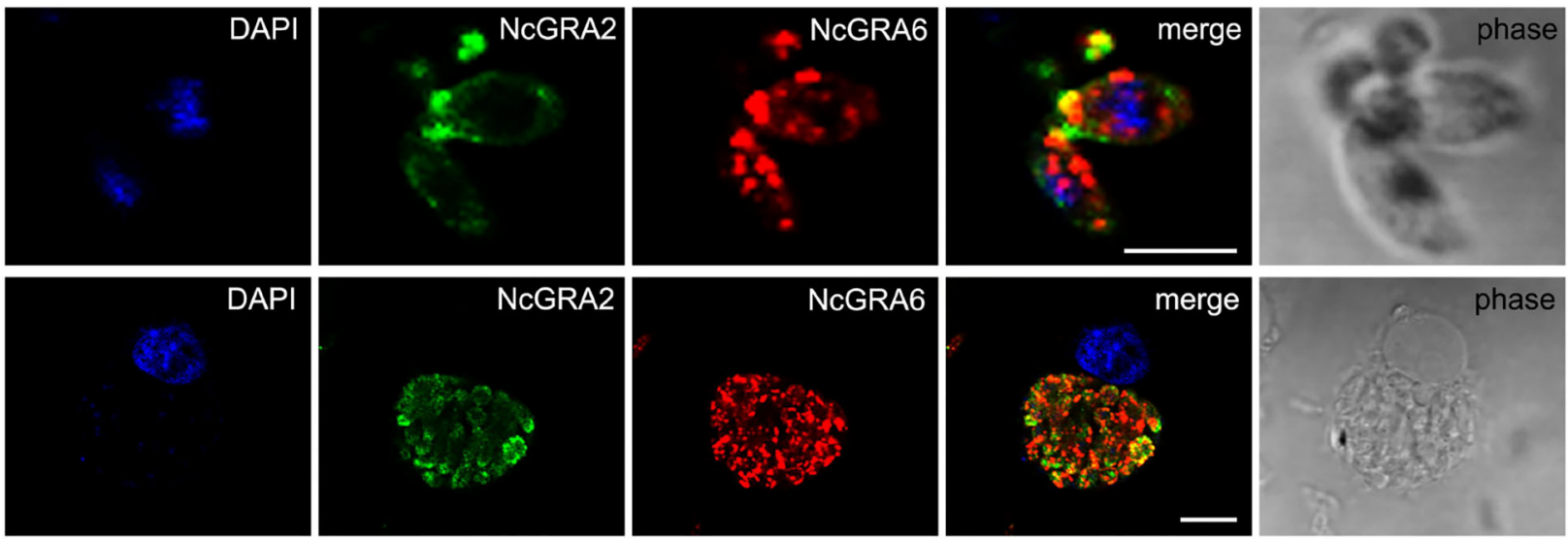

B

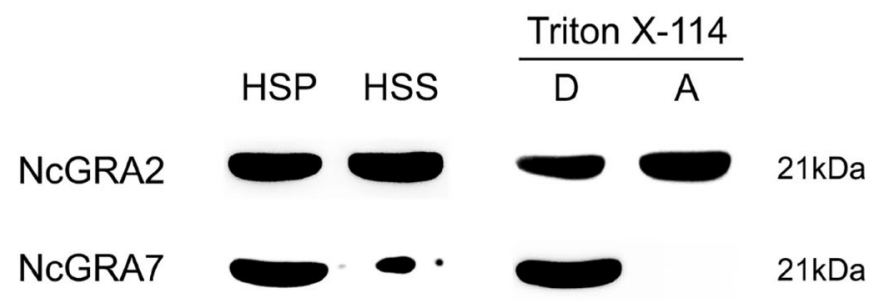

FIGURE 1 | Subcellular localization and morphology analysis of the NcGRA2 protein in parasites and infected cells. (A) Immunofluorescence colocalization of NcGRA2 and NcGRA6 proteins in parasites and infected cells. The nucleus was stained with DAPI. The NcGRA2 protein and NcGRA6 protein were labeled with FITC and Cy3, respectively. Bar $=5 \mu \mathrm{m}$. (B) Morphology analysis of the NcGRA2 protein in parasite-infected cells. HSS represents the soluble cell fraction after high-speed centrifugation. HSP represents the insoluble cell fraction after high-speed centrifugation. The HSPs were then sonicated and centrifuged at high speed, and pellets (P) and supernatants (S) were obtained. The obtained pellets were further dissolved in denaturing agents, and the detergent phase (D) and aqueous phase (A) were obtained. The NcGRA7 protein was used as a control to detect the purity of fractions.

was absent in the $\triangle \mathrm{NcGRA} 2$ strain. These data indicated that the NcGRA2 protein was not secreted into the PV and that the $\triangle \mathrm{NcGRA} 2$ strain was successfully constructed.

\section{Roles of NcGRA2 in N. caninum Invasion and Proliferation}

After invasion, N. caninum enters into host cells, replicates in the PV, egresses out of the PV, and invades uninfected cells. Plaque assays are indicators that comprehensively evaluate the viability of parasites. In this study, to compare the influence of the NcGRA2 gene on the viability of $N$. caninum, host cells were individually inoculated with $\mathrm{Nc}-1$ strain tachyzoites and $\triangle \mathrm{NcGRA} 2$ strain tachyzoites to carry out plaque assays, and untreated cells were used as a negative control (NC); the pixels of each plaque (pi) were determined. As shown in Figures 3A,B, there were no plaques found in the NC group; in contrast, larger plaques existed in the Nc-1 group, and smaller plaques existed in the NcGRA2 disruption group. Compared with the Nc-1 group, the pi value was obviously downregulated in the $\triangle$ NcGRA2 group $(* p<0.05)$.

The difference in plaque formation may be related to invasion, egress, or replication. To determine which critical process significantly influences the viability of parasites in host cells, we first measured the invasion ability after treatment time points of 20,40, and $60 \mathrm{~min}$. As shown in Figure 3C, along with the prolonged incubation time, the invasion percentages were increased. However, no significance was observed between the $\mathrm{Nc}-1$ strain group and the $\triangle \mathrm{NcGRA} 2$ strain group, indicating that the NcGRA2 gene was not involved in N. caninum invasion ability.

Next, we carried out egress assays to evaluate the influence of the NcGRA2 gene on the viability of parasites in host cells. Monolayer HFF cells were incubated with parasites and then stimulated with a $\mathrm{Ca}^{2+}$ ionophore. The egress percentages were calculated by counting the labeled parasites. As displayed in Figure 3D, although the egress percentages in the $\triangle$ NcGRA2 strain were lower than those in the Nc-1 strain group, the difference was not significant $(p>0.05)$. In addition, DMSO, the solvent used for A23187, had a relatively low influence on egress ability. Thus, we inferred that the NcGRA2 gene also had no function in N. caninum egress out of PV.

The proliferation assays were carried out by counting the amounts of parasites in each PV after different inoculation time points of 6, 12, 24, and $36 \mathrm{~h}$. As shown in Figure 3E, at the initial 


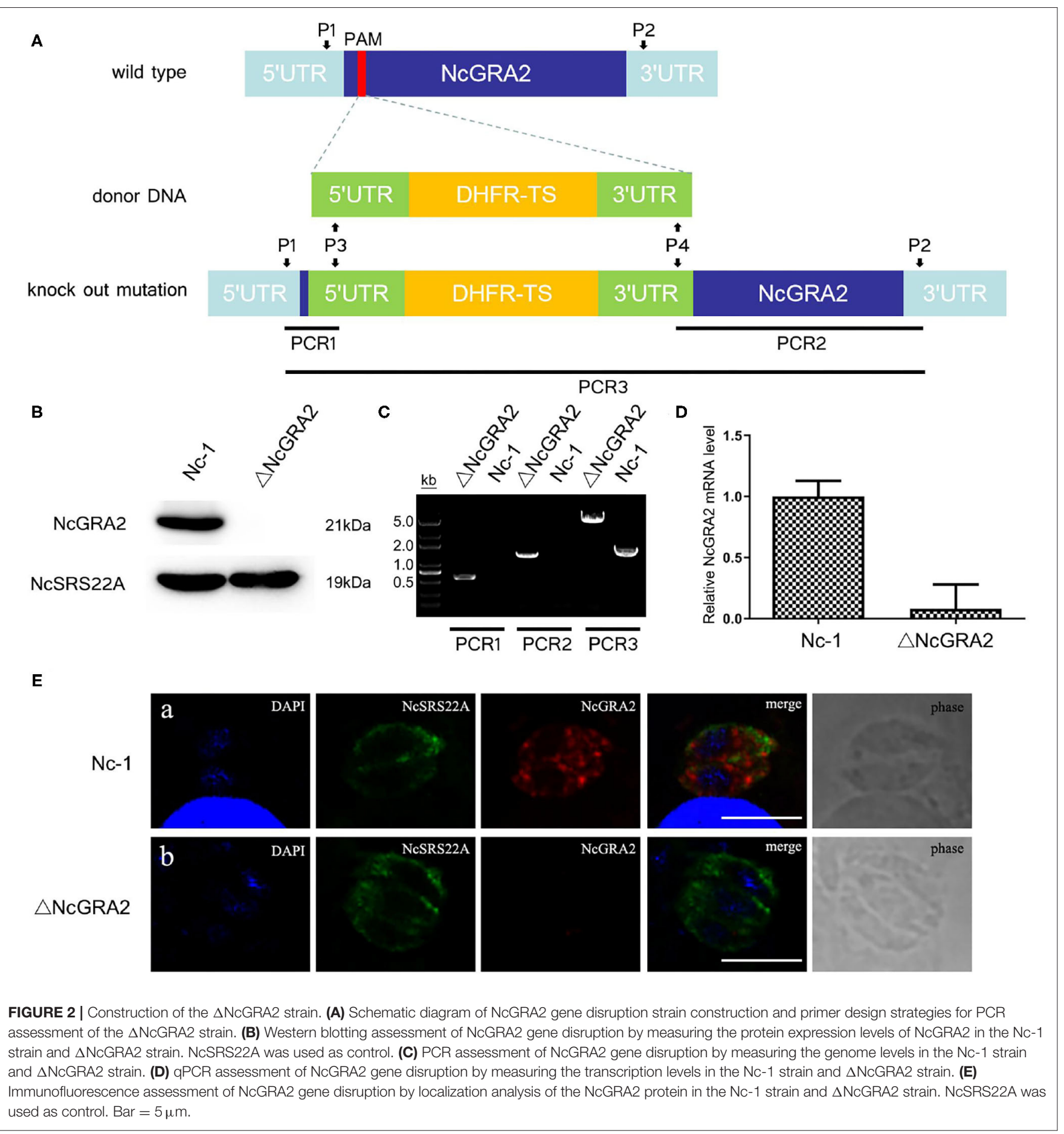

infection stage, a large number of vacuoles contained one or two parasites; moreover, no significant difference was found in these two groups $(p>0.05)$. At $12 \mathrm{~h}$, the numbers of parasites became larger in both groups, with more than half of the vacuoles containing two or four parasites; in addition, the total number of parasites in the Nc-1 group was obviously larger than that in the $\triangle$ NcGRA2 group $(* p<0.05)$. As the infection time increased, the proliferation rate increased in the Nc-1 group, accompanied by most vacuoles containing eight parasites; in contrast, only four parasites were present in most vacuoles of the $\triangle \mathrm{NcGRA} 2$ group. The total number of parasites in the $\triangle \mathrm{NcGRA} 2$ group was significantly less than that in the $\mathrm{Nc}-1$ group at both 24- and $36-\mathrm{h}$ time points $\left({ }^{* *} p<0.01\right)$. Overall, these data illustrated that the NcGRA2 gene could control $N$. caninum replication in the PV and influence the viability of parasites in host cells. 
A

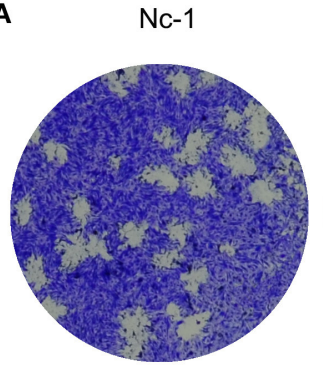

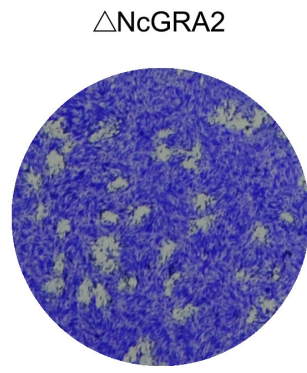
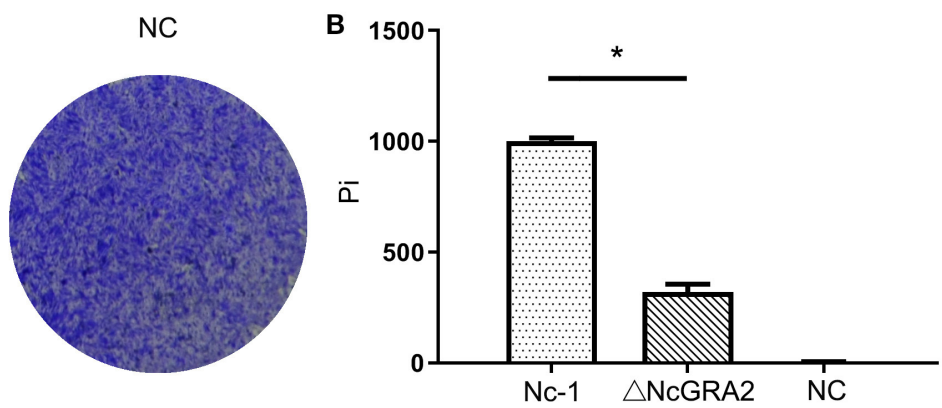

C
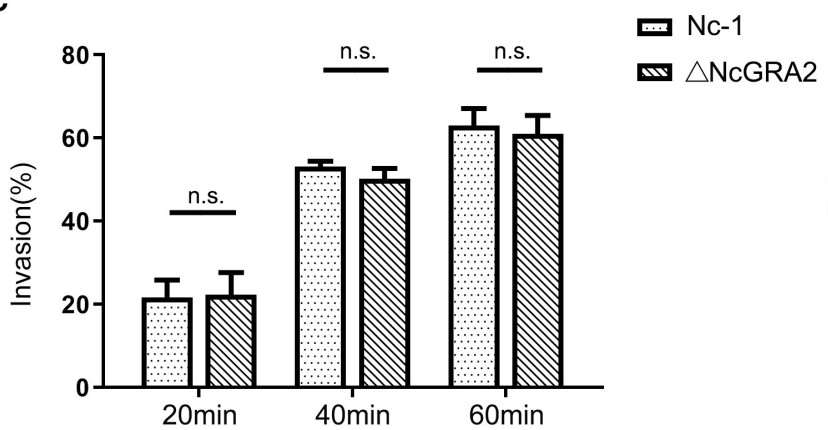

D

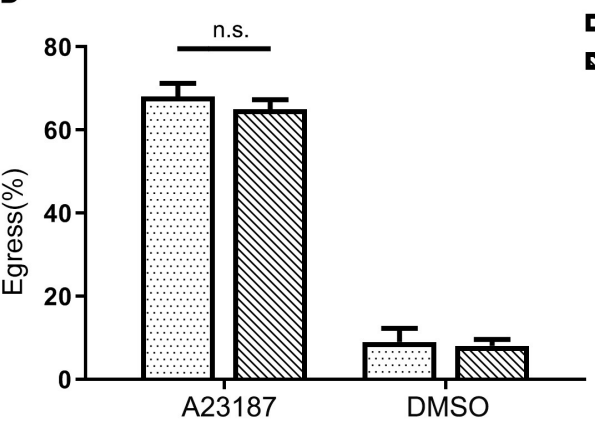

E

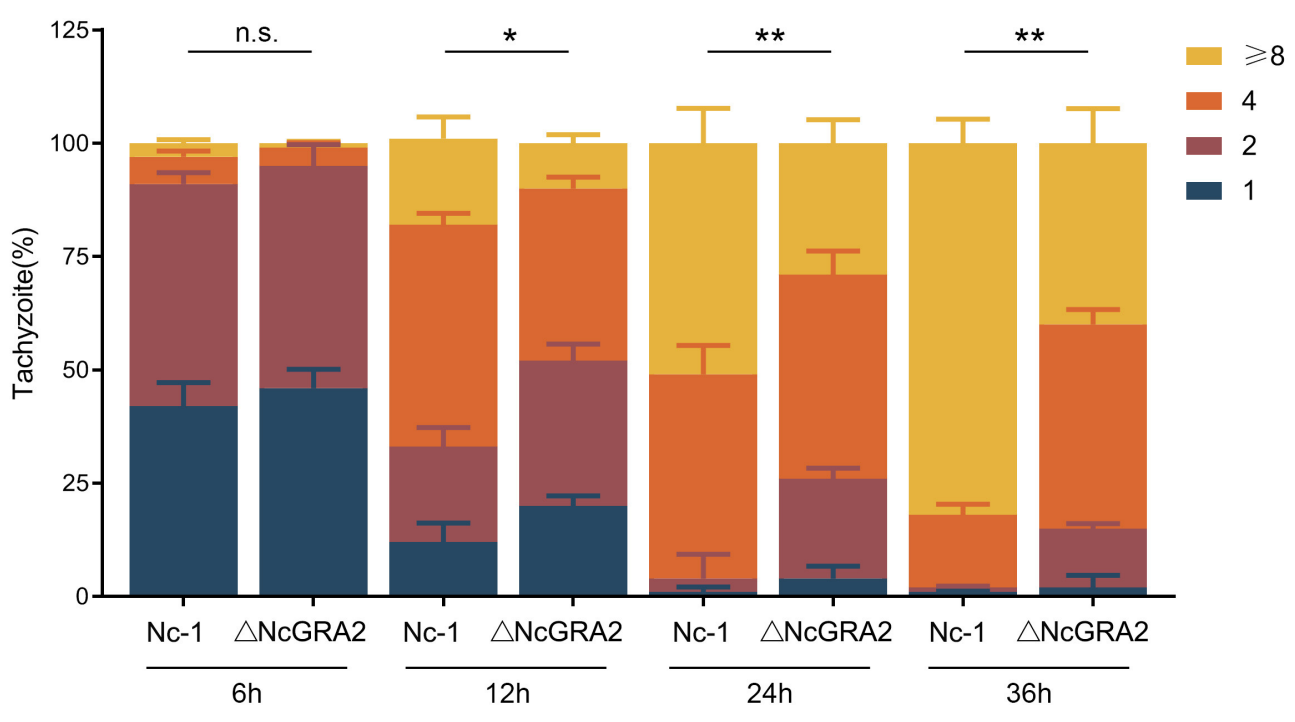

FIGURE 3 | Disruption of the NcGRA2 gene adversely affects virulence in vitro. (A,B) Plaque assays were carried out by inoculation of parasites onto HFF cells previously coated on six-well plates (80-120 tachyzoites per well), followed by culturing for 7 days. The Nc-1 group was used as a positive control, and the NC group was used as a negative control. After staining with crystal violet, the cells were imaged, and then pixels of plaques (Pi) were measured by randomly selecting no fewer than 20 plaques and counting with pixel points in Photoshop CS5 software. (C) Invasion assays were conducted through inoculation of the Nc-1 strain and $\triangle$ NcGRA2 strain with an infection dose of $1 \times 10^{5}$ tachyzoites/well onto HFF cells coated on coverslips in 6-well plates and then culturing for the indicated time. Immunofluorescence assays with anti-NcSRS22A and anti-NcGRA2 antibodies were carried out to label the total parasites and extracellular parasites, and then the invasion percentage was calculated. (D) Egress assays were performed by inoculation of the Nc-1 strain and $\triangle$ NcGRA2 strain onto HFF cells coated on coverslips in six-well plates $\left(1 \times 10^{5}\right.$ tachyzoites/well) and culturing for $48 \mathrm{~h}$. After stimulation with the $\mathrm{Ca}^{2+}$ ionophore A23187, immunofluorescence assays with anti-NcGRA2 antibodies were conducted, and the egress percentage was measured from 100 randomly selected vacuoles. The dilution buffer, DMSO, was used as a negative control. (E) Intracellular parasite replication assays were measured by pretreatment of HFF cells with the Nc-1 strain and $\Delta$ NcGRA2 strain $\left(1 \times 10^{6}\right.$ tachyzoites/well) for $4 \mathrm{~h}$ and then culturing for the indicated time. Immunofluorescence assays with anti-NcSRS22A antibodies were performed, and parasite replication was determined by 100 randomly selected vacuoles. ${ }^{*} p<0.05,{ }^{* \star} p<0.01$, and n.s. represents no significance vs. the Nc-1 group. 


\section{Disruption of the NcGRA2 Gene Decreased N. caninum Virulence}

Virulence in vivo was comprehensively evaluated by establishing infection models. For the acute infection, mice were injected i.p. with a high dose of the Nc-1 strain or NcGRA2 disruption strain $\left(2 \times 10^{7}\right.$ per mouse $)$ and monitored for the survival days. As shown in Figure 4A, inoculation of Nc-1 strain tachyzoites caused mice to begin to die at day 6 , and all the mice died by day 9 ; however, inoculation of $\triangle$ NcGRA2 strain tachyzoites caused $20 \%$ of mice to die at day 9 , and $20 \%$ of mice were still alive at day 40 . The survival percentage in the $\triangle$ NcGRA2 group was obviously higher than that in the Nc-1 group $(p=0.0041)$. These data indicated that the NcGRA2 gene played roles in the pathogenicity of $N$. caninum and that knockout of the NcGRA2 gene could prolong the survival time of the hosts.

To compare the influence of the Nc-1 strain and the NcGRA2 disruption strain tachyzoites on tissue damage, non-lethal doses of tachyzoites $\left(2 \times 10^{6}\right.$ tachyzoites per mouse $)$ were inoculated i.p. into mice. Tissues were separated, and the amounts of parasites were determined at 3, 7, and $15 \mathrm{dpi}$. As shown in Figure 4B, at the initial infection stage of $3 \mathrm{dpi}$, all the separated tissues, including hearts, livers, spleens, lungs, kidneys, and brains, had relatively high parasite burdens in both groups. Moreover, parasite burdens were significantly decreased in the $\triangle$ NcGRA2 group compared with the $\mathrm{Nc}-1$ group in hearts and kidneys $\left({ }^{*} p<0.05\right)$; however, there were no significant differences in other tissues $(p>0.05)$. At 7 and $15 \mathrm{dpi}$, lungs and brains were the major parasite reserve organs for the Nc1 strain infection group; in contrast, the NcGRA2 disruption group had low levels of parasites, especially in the lungs $\left({ }^{*} p<\right.$ 0.05). Similar to heart and liver tissues, although at low levels of parasite burden when compared with the initial infection stage, the parasite amounts were significantly lower in the $\triangle$ NcGRA2 group than in the Nc-1 group $\left({ }^{*} p<0.05\right)$. Low levels of parasite burdens were detected in the spleen and kidney groups at 7 and $15 \mathrm{dpi}$ (Figures 4C,D). Overall, the lung and brain tissues were the storage organs of $N$. caninum, and disruption of the NcGRA2 gene could obviously decrease the parasite levels in targeted organs and may further lower its pathogenicity.

Histopathological changes were detected in the targeted organs. Compared with the NC group at $15 \mathrm{dpi}$, Nc-1 straininfected mice at 15 dpi displayed significantly thickened alveolar mass in lung tissues, obvious inflammatory cell infiltration and small focal necrosis in liver tissues, and glial cell proliferation in brain tissues. For the $\triangle \mathrm{NcGRA} 2$ group, histopathological changes in lung tissues displayed slightly widened alveolar masses at 3, 7, and 15 dpi. Liver tissues showed slight inflammatory cell infiltration surrounding the central veins throughout the infection stage and partial denaturation at 15 dpi. Brain tissues only displayed glial cell proliferation at $7 \mathrm{dpi}$. Furthermore, no changes in heart tissues were found in any of the infection groups (Figure 5). These data indicated that the NcGRA2 gene played roles in regulating $N$. caninum-induced tissue damage, especially in target organs of the lungs. Disruption of the NcGRA2 gene could decrease the pathogenicity of $N$. caninum.

\section{DISCUSSION}

During N. caninum invasion into host cells, many different kinds of secretory antigens are involved in this process and play various biological functions. In our previous studies, we found that GRA proteins increased most significantly compared with other secretory antigens of MICs and ROPs (unpublished data). This illustrated that GRAs were the most important components of PV and may play critical roles in the proliferation of N. caninum. In $T$. gondii, based on the different positions where they are released, GRAs are divided into three forms: soluble proteins, such as GRA1 targeted the lumen of PV; integral membrane proteins, such as GRA3 localized to the delimiting membrane of the PV; and soluble and membrane-associated proteins, such as GRA2 situated in the IVN, which belongs to the reticulum of membranous tubules (39). Although the exact mechanism remains unclear, the amino acid sequence analysis of some GRAs existing in the transmembrane region suggests that they may be key factors associated with membranes. It has been verified that tubulogenic proteins of GRA2 and GRA6 can stabilize the IVN structure in the PV of T. gondii and display great significance in parasite proliferation $(21,25,40,41)$. The roles of NcGRA6 have been elucidated $(29,38)$; however, research on the roles of NcGRA2 in N. caninum is limited. In this study, NcGRA2 sequences were obtained from the $N$. caninum $\mathrm{Nc}-1$ strain and shared $100 \%$ amino acid sequence homology with previously published NcGRA2 in the $N$. caninum NC-Liverpool strain (NCLIV_045650). In Ellis' published article, the NcGRA2 amino acid sequences were released into GenBank (AAG28489.1), and there are $100 \%$ homology between NcGRA2 amino acid sequences in NCLIV_045650 and AAG28489.1 (26). A bioinformatics analysis showed that only signal peptides existed and that there were no transmembrane regions in the NcGRA2. In contrast, HSP and HSS analysis showed that NcGRA2 existed in the PV in soluble and membrane-bound forms. An in-depth analysis of HSP by dissolving in Triton X-114 showed that NcGRA2 associated with PVM as a transmembrane protein and a membrane-associated protein. Interestingly, our prediction analysis showed that there was no transmembrane region. In T. gondii, GRA2 was embedded in the IVN of PV through the structures of two AAHs $(19,21)$. Thus, the protein structure of NcGRA2 was further analyzed in ToxoDB, which displayed that NcGRA2 and TgGRA2 had similar AAH distribution, inferring that the transmembrane structure in N. caninum may also be formed through embedding in the IVN of PV with the aid of AAHs. To further characterize the localization of NcGRA2, immunofluorescence assays were carried out by assessing colocalization with NcGRA6. Previous studies showed through immunoelectron microscopy analysis that NcGRA6 was specifically localized in the GRAs of $N$. caninum tachyzoites and IVN of PV (29). Most GRAs could colocalize with NcGRA6 in tachyzoites except for NcGRA1, NcGRA3, NcGRA5, or NcGRA12, which may share different protein secretory pathways or synthesis locations (unpublished data). Moreover, most GRAs colocalized with NcGRA6 in the PV of infected MDBK cells and were involved in the composition of the IVN, except 


\section{A}

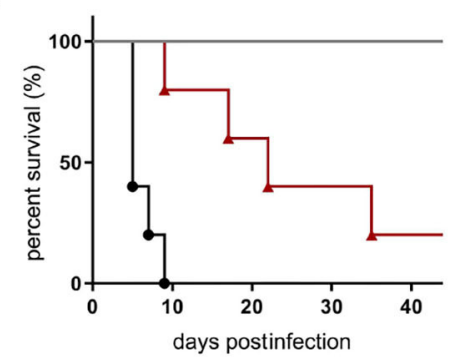

$$
\begin{aligned}
& \rightarrow \mathrm{Nc}-1 \\
& +\triangle \mathrm{NcGRA} 2 \\
& \rightarrow \mathrm{NC}
\end{aligned}
$$

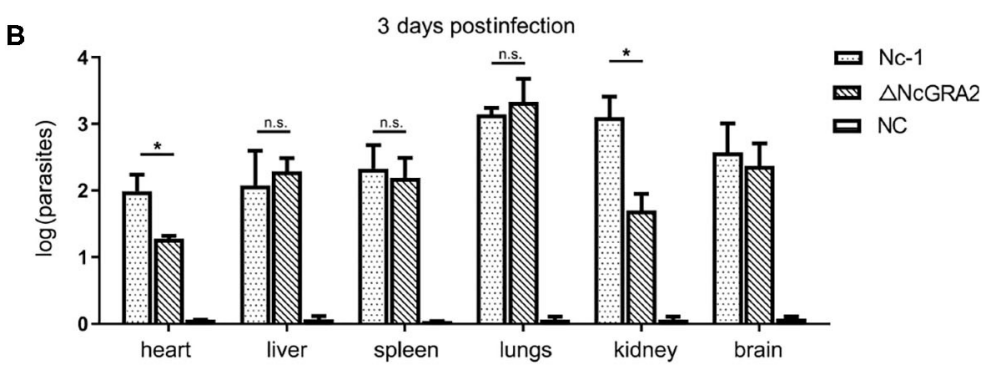

$\mathrm{C}$

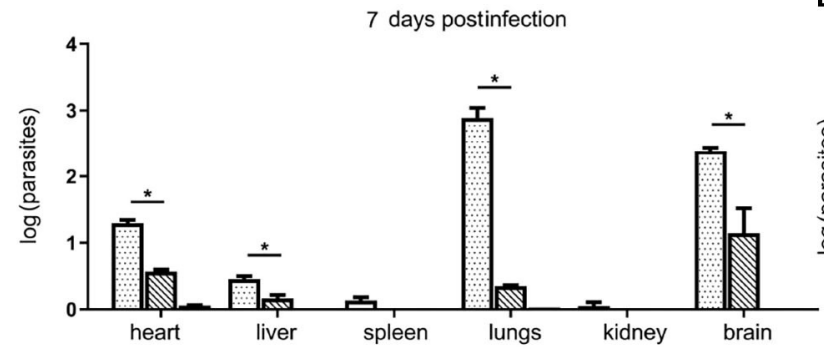

D

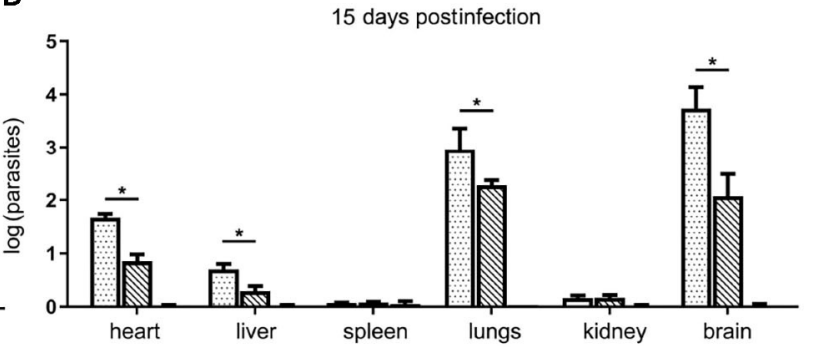

FIGURE 4 | Disruption of the NcGRA2 gene decreases the virulence in vivo. (A) Monitoring of mouse survival after injection with the Nc-1 strain and $\triangle$ NcGRA2 strain. The female BALB/C mice were injected i.p. with $2 \times 10^{7}$ tachyzoites per mouse. The survival time were monitored for 40 days. The NC group was treated with an equal volume of PBS. (B-D) Determination of parasite burden in different tissues at the indicated time. The female BALB/C mice were injected i.p. with $2 \times 10^{6}$ tachyzoites per mouse. Then, the mice were humanely euthanized, and heart, liver, spleen, lung, kidney, and brain tissues were isolated. The NC group was treated with equal volume of PBS. Parasites burden was determined by qPCR. * $p<0.05$, and n.s. represents no significance.

for NcGRA5, which was an integral transmembrane protein localized in the PVM and not involved in the composition of the IVN (unpublished data). Thus, NcGRA6 was used as an indicator to preliminarily explore the localization of NcGRA2 in tachyzoites and infected cells. From the colocalization analysis in the tachyzoites, the NcGRA2 protein was mostly colocalized with NcGRA6, which indicates that NcGRA2 could be secreted from GRAs of $N$. caninum. From the colocation analysis in the infected cells, NcGRA2 protein was completely colocated with NcGRA6, indicating that NcGRA2 was also a constituent of the IVN. Similar to our results, the NcGRA2 location in bradyzoites was within the vacuoles; however, it was also found in the vacuole periphery, although not pronounced, which was different from that in tachyzoites (27). In T. gondii, results of GRA2 gene disruption and TgGRA2 gene complement showed that the Nterminal domain and the three main amphoteric $\alpha$-helices were all necessary for IVN formation, which indicated that TgGRA2 involved in the formation of IVN $(25,42)$. Our results found that NcGRA2 was also localized in the IVN; however, its roles on the IVN formation still need to be further determined in the future.

To further determine the gene function of NcGRA2 in N. caninum, CRISPR/Cas9 technology was used to construct the NcGRA2 disruption strain. For the study of protozoon of the phylum Apicomplexa, the CRISPR/Cas9 system was used to construct a model organism T. gondii gene knockout strain in 2014 for the first time. The CRISPR/Cas9 system mainly contains two parts: the Cas 9 dsDNA nuclease and guide RNA, a cofactor used to specifically select targeted genes and cause breaks in dsDNA (43). Research has found that there are many repair methods for double-stranded breaks, including HDR and NHEJ, in T. gondii (44, 45). The HDR pathway is the most classical method; however, it is a repair mechanism with a lengthy period and a low efficiency and is limited by a relatively long homologous arm. Therefore, a relatively more efficient method of NHEJ has been widely applied in the study of $T$. gondii. Using the CRISPR/Cas9 system in T. gondii significantly improved the gene editing efficiency while avoiding the drawbacks of traditional manipulation (46-49). N. caninum also belongs to the phylum Apicomplexa and shares relatively high homology with T. gondii. Previous protein function research on N. caninum mainly used the homologous recombination method (33), which shared a lower gene editing efficiency and higher failure rate. Testing the gene functions in $N$. caninum was previously severely compromised by limited technologies until the T. gondii CRISPR/Cas9 system was used to generate the NcGRA7 gene disruption strain for the first time in 2018 (50). Considering the experience obtained with T. gondii, we made initial attempts to construct an NcGRA2 gene disruption strain with the T. gondii CRISPR/Cas9 system (51); however, we failed, with a low gene editing efficiency observed. Next, we found that Yang et al. attempted to utilize the strong RNA polymerase III $N$. caninum U6 promoter instead of T. gondii to efficiently knock out the NcGRA17 gene (52). Moreover, Zhao et al. used pNc-SAG1::CAS9-U6::sgUPRT containing 


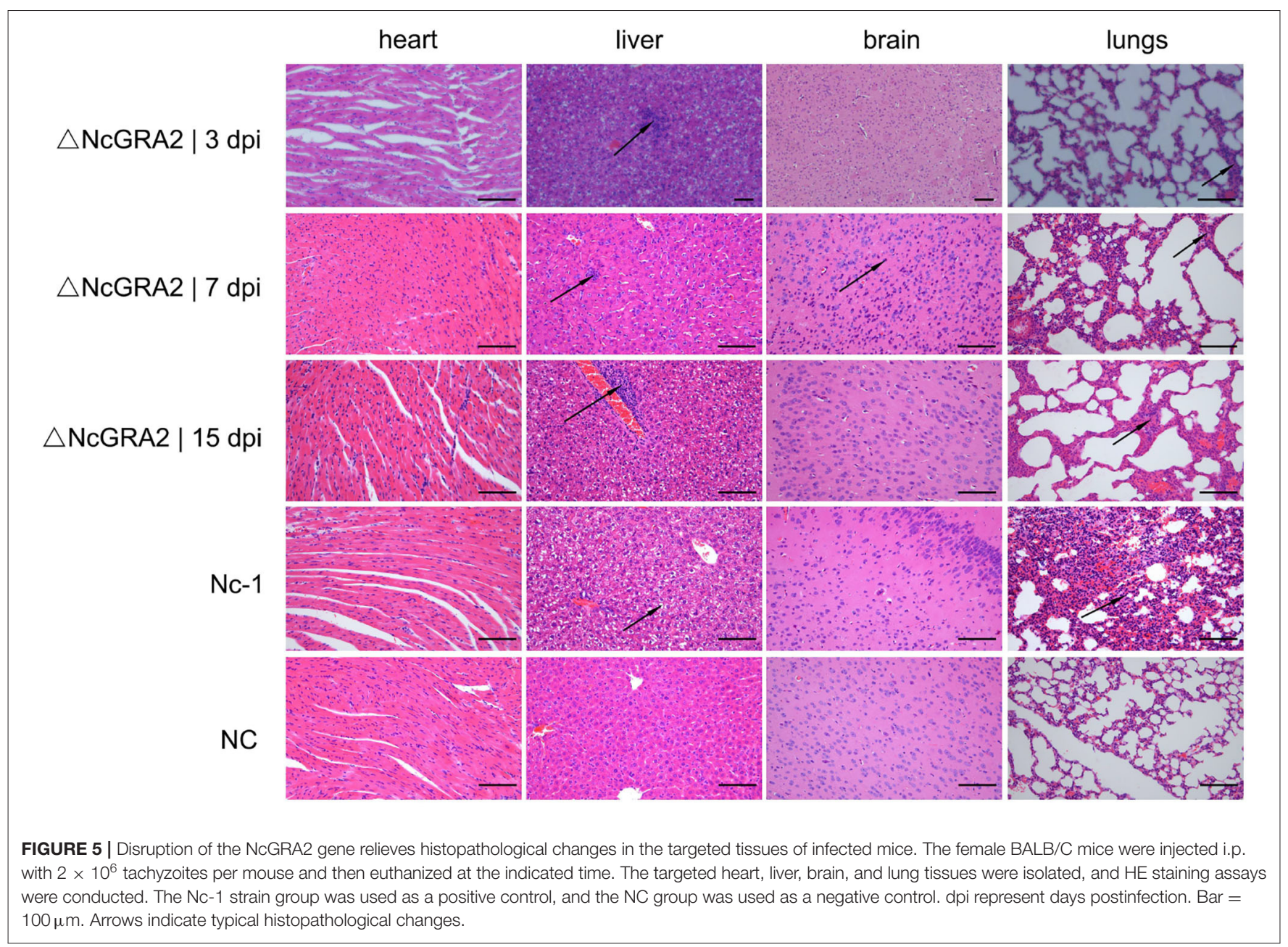

the $N$. caninum U6 promoter to successfully generate an NcGRA6 gene knockout strain (29). In this study, based on the N. caninum $\mathrm{U} 6$ promoter and sgRNA sequences for NcGRA2, we constructed a pNc-SAG1::CAS9-U6::sgGRA2 and then generated a $\triangle$ NcGRA2 strain through coelectrotransforming the gene editing plasmid and DHFR-TS cassette into Nc-1 tachyzoites. sgGRA2 is regulated by the $N$. caninum U6 promoter, and Cas9 transcription is regulated by the SAG1 promoter and terminator of $N$. caninum. The gene editing system disrupts the NcGRA2 gene by insertion of the DHFR-TS marker. Under pyrimethamine pressure screening and single clone culturing, an NcGRA2 gene disruption strain was finally obtained. Overall, the CRISPR/Cas9 system could make gene function research available for a variety of parasitic protozoa with a high efficiency (53-57).

Although limited research has focused on the protein functions of $N$. caninum, studies on the protein functions of T. gondii provide a reference. In T. gondii, TgGRA2 expression could be detected both in tachyzoites at different growing stages and in the IVN of the PV. Disruption of the TgGRA2 gene reduced IVN formation by inhibiting Rab11A vesicle formation and influenced the pathogenicity of T. gondii $(19,41)$. To date, only two studies have focused on GRA function research in $N$. caninum virulence by constructing $N$. caninum knockout strains, namely, GRA6 and GRA17 $(29,52)$. Inoculation of the $\triangle \mathrm{NcGRA} 6 \mathrm{Nc}-1$ strain prolonged the mouse survival time to 24 days compared with the wild type $\mathrm{Nc}-1$ strain with a survival time of 8 days (29). The $\Delta$ NcGRA17-infected mice were all alive during the monitored 60 days; in contrast, all the mice died in the wild type Nc-1 strain group (52). However, the function of NcGRA2 has not been fully clarified. The association of NcGRA2 and the pathogenicity of $N$. caninum need to be determined. In this study, we showed that disruption of the NcGRA2 gene reduced tachyzoite proliferation and decreased pathogenicity in mice, accompanied by higher survival rates and lower tissue damage and parasite burden. For the evaluation of egress ability, similar to NcGRA6, the $\triangle$ NcGRA2 group shared no significant difference compared with that in the wild-type group (29). Results illustrate that these two NcGRA proteins do not involve in the egress process in tachyzoite-infected cells. Overall, these data highlighted the roles of NcGRA2 in the virulence of $N$. caninum. 


\section{CONCLUSIONS}

We characterized the $N$. caninum GRA protein NcGRA2, constructed an NcGRA2 gene disruption strain based on the Nc1 strain with the CRISPR/Cas9-directed genome editing system, and highlighted the roles of NcGRA2 in N. caninum virulence through in vivo and in vitro assays.

\section{DATA AVAILABILITY STATEMENT}

The original contributions presented in the study are included in the article/Supplementary Material, further inquiries can be directed to the corresponding author/s.

\section{ETHICS STATEMENT}

The animal study was reviewed and approved by Animal Welfare and Research Ethics Committee of Jilin University.

\section{AUTHOR CONTRIBUTIONS}

JD designed the research. JD and NZ conducted the research. PG, JL, LC, XW, XL, and JY analyzed the data. JD and PZ wrote the

\section{REFERENCES}

1. Bjerkas I, Mohn SF, Presthus J. Unidentified cyst-forming sporozoon causing encephalomyelitis and myositis in dogs. Z Parasitenkd. (1984) 70:2714. doi: $10.1007 / \mathrm{BF} 00942230$

2. Dubey JP, Lindsay DS. A review of Neospora caninum and neosporosis. Vet Parasitol. (1996) 67:1-59. doi: 10.1016/S0304-4017(96)01035-7

3. Frenkel JK, Smith DD. Determination of the genera of cyst-forming coccidia. Parasitol Res. (2003) 91:384-9. doi: 10.1007/s00436-003-0969-4

4. Lindsay DS, Dubey JP. Canine neosporosis. J Vet Parasitol. (2000) 14:5770. doi: 10.2147/VMRR.S76969

5. Reid MP, Wahl LC, Ellis JT. Research into Neospora caninumwhat have we learnt in the last thirty years? Pathogens. (2020) 9:505. doi: 10.3390/pathogens 9060505

6. Ansari-Lari M. Bovine neosporosis in Iran: a systematic review and meta-analysis. Prev Vet Med. (2020) 176:104913. doi: 10.1016/j.prevetmed.2020.104913

7. Satragno D, Pavón-Rocha AJ, Rábago-Castro JL, Cruz-Hernández NI. High seroprevalence of Neospora caninum in dogs with clinical suspicion of neosporosis in Montevideo, Uruguay. Rev Argent Microbiol. (2020) 52:1656. doi: 10.1016/j.ram.2019.03.007

8. Dubey JP, Schares G, Ortega-Mora LM. Epidemiology and control of neosporosis and Neospora caninum. Clin Microbiol Rev. (2007) 20:32367. doi: 10.1128/CMR.00031-06

9. Reichel MP, Ayanegui-Alcérreca MA, Gondim LP, Ellis JT. What is the global economic impact of Neospora caninum in cattle - the billion dollar question. Int J Parasitol. (2013) 43:133-42. doi: 10.1016/j.ijpara.2012.10.022

10. Francia ME, Striepen B. Cell division in apicomplexan parasites. Nat Rev Microbiol. (2014) 12:125-36. doi: 10.1038/nrmicro3184

11. Reid AJ, Vermont SJ, Cotton JA, Harris D, Hill-Cawthorne GA, Könen-Waisman S, et al. Comparative genomics of the apicomplexan parasites Toxoplasma gondii and Neospora caninum: coccidia differing in host range and transmission strategy. PLoS Pathog. (2012) 8:e1002567. doi: 10.1371/journal.ppat.1002567

12. Hemphill A, Gottstein B, Kaufmann H. Adhesion and invasion of bovine endothelial cells by Neospora caninum. Parasitology. (1996) 112:18397. doi: $10.1017 / \mathrm{s} 0031182000084754$ manuscript. PG and XZ directed the project. All authors have read and approved the manuscript.

\section{FUNDING}

This project support was provided by the National Natural Science Foundation of China (Grant No. 31902296), National Key Basic Research Program (973 program) of China (Grant No. 2015 CB 150300), and China Postdoctoral Science Foundation (Grant No. 2019M661217).

\section{ACKNOWLEDGMENTS}

We are grateful to Professor Shen B. (Huazhong Agricultural University, China) for kindly providing the pSAG1::CAS9U6::sgUPRT plasmid.

\section{SUPPLEMENTARY MATERIAL}

The Supplementary Material for this article can be found online at: https://www.frontiersin.org/articles/10.3389/fvets. 2021.634612/full\#supplementary-material
13. Gubbels MJ, Duraisingh MT. Evolution of apicomplexan secretory organelles. Int J Parasitol. (2012) 42:1071-81. doi: 10.1016/j.ijpara.2012.09.009

14. Beck JR, Chen AL, Kim EW, Bradley PJ. RON5 is critical for organization and function of the Toxoplasma moving junction complex. PLoS Pathog. (2014) 10:e1004025. doi: 10.1371/journal.ppat.1004025

15. Ahn HJ, Kim S, Kim HE, Nam HW. Interactions between secreted GRA proteins and host cell proteins across the paratitophorous vacuolar membrane in the parasitism of Toxoplasma gondii. Korean J Parasitol. (2006) 44:30312. doi: $10.3347 / \mathrm{kjp} .2006 .44 .4 .303$

16. Cesbron-Delauw M-F. Dense-granule organelles of Toxoplasma gondii: their role in the host parasite relationship. Parasitol Today. (1994) 10:29396. doi: 10.1016/0169-4758(94)90078-7

17. Nam HW. GRA proteins of Toxoplasma gondii: maintenance of hostparasite interactions across the parasitophorous vacuolar membrane. Korean J Parasitol. (2009) 47:S29-37. doi: 10.3347/kjp.2009.47.S.S29

18. Guevara RB, Fox BA, Bzik DJ. Toxoplasma gondii parasitophorous vacuole membrane-associated dense granule proteins regulate maturation of the cyst wall. Pathogens. (2020) 15:e00851-19. doi: 10.1128/mSphere.00851-19

19. Bittame A, Effantin G, Pètre G, Ruffiot P, Travier L, Schoehn G, et al. Toxoplasma gondii: Biochemical and biophysical characterization of recombinant soluble dense granule proteins GRA2 and GRA6. Biochem Biophy Res Co. (2015) 459:107-12. doi: 10.1016/j.bbrc.2015.02.078

20. Magno RC, Lemgruber L, Vommaro RC, Souza WD, Attias M. Intravacuolar network may act as a mechanical support for Toxoplasma gondii inside the parasitophorous vacuole. Microsc Res Techniq. (2005) 67:4552. doi: 10.1002/jemt.20182

21. Travier L, Mondragon R, Dubremetz JF, Musset K, Mondragon M, Gonzalez $\mathrm{S}$, et al. Functional domains of the Toxoplasma GRA2 protein in the formation of the membranous nanotubular network of the parasitophorous vacuole. Int $J$ Parasitol. (2008) 38:757-73. doi: 10.1016/j.ijpara.2007. 10.010

22. Mercier C, Howe DK, Mordue D, Lingnau M, Sibley LD. Targeted disruption of the GRA2 locus in Toxoplasma gondii decreases acute virulence in mice. Infect Immun. (1998) 66:4176-82. doi: 10.1007/BF02962269

23. Reese ML, Boothroyd JC. A helical membrane-binding domain targets the Toxoplasma ROP2 family to the parasitophorous vacuole. Traffic. (2009) 10:1458-70. doi: 10.1111/j.1600-0854.2009.00958.x 
24. Niedelman W, Gold DA, Rosowski EE, Sprokholt JK, Lim D, Arenas AF, et al. The rhoptry proteins ROP18 and ROP5 mediate Toxoplasma gondii evasion of the murine, but not the human, interferon-gamma response. PLoS Pathog. (2012) 8:e1002784. doi: 10.1371/journal.ppat.1002784

25. Mercier C, Dubremetz JF, Rauscher B, Lecordier L, Sibley LD, CesbronDelauw MF. Biogenesis of nanotubular network in Toxoplasma parasitophorous vacuole induced by parasite proteins. Mol Biol Cell. (2002) 13:2397-409. doi: 10.1091/mbc.E02-01-0021

26. Ellis JT, Ryce C, Atkinson R, Balu S, Jones P, Harper PAW. Isolation, characterization and expression of a GRA2 homologue from Neospora caninum. Parasitology. (2000) 120:383-90. doi: 10.1017/S0031182099005673

27. Vonlaufen N, Guetg N, Naguleswaran A, Müller N, Björkman C, Schares $\mathrm{G}$, et al. In vitro induction of Neospora caninum bradyzoites in vero cells reveals differential antigen expression, localization, and host-cell recognition of tachyzoites and bradyzoites. Infect Immun. (2004) 72:57683. doi: 10.1128/iai.72.1.576-583.2004

28. Ellis J, Miller C, Quinn H, Ryce C, Reichel MP. Evaluation of recombinant proteins of Neospora caninum as vaccine candidates (in a mouse model). Vaccine. (2008) 26:5989-96. doi: 10.1016/j.vaccine.2008.08.043

29. Zhao PP, Zhang N, Dong JQ, Li JH, Wang XC, Li X, et al. Effects of dense granular protein 6 (GRA6) disruption on Neospora caninum virulence. Front Vet Sci. (2020) 7:562730. doi: 10.3389/fvets.2020.562730

30. Fohl LM, Roos DS. Fitness effects of DHFR-TS mutations associated with pyrimethamine resistance in apicomplexan parasites. Mol Microbiol. (2003) 50:1319-27. doi: 10.1046/j.1365-2958.2003.03756.x

31. Sibley LD, Niesman IR, Parmley SF, Cesbron-Delauw MF. Regulated secretion of multi-lamellar vesicles leads to formation of a tubulo-vesicular network in host-cell vacuoles occupied by Toxoplasma gondii. J Cell Sci. (1995) 108:1669-77.

32. Adjogblea KDZ, Mercier C, Dubremetz JF, Hucke C, MacKenzie CR, CesbronDelauwb MF, et al. GRA9, a new Toxoplasma gondii dense granule protein associated with the intravacuolar network of tubular membranes. Int $J$ Parasitol. (2004) 34:1255-64. doi: 10.1016/j.ijpara.2004.07.011

33. Ma L, Liu J, Li M, Fu Y, Zhang X, Liu Q. Rhoptry protein 5 (ROP5) is a key virulence factor in Neospora caninum. Front Microbiol. (2017) 8:370. doi: $10.3389 /$ fmicb. 2017.00370

34. Li M, Wang H, Liu J, Pan H, Ma L, Liu Q. The apoptotic role of metacaspase in Toxoplasma gondii. Front Microbiol. (2016) 6:1560. doi: 10.3389/fmicb.2015.01560

35. Soldati D, Meissner M. Toxoplasma as a novel system for motility. Curr Opin Cell Biol. (2004) 16:32-40. doi: 10.1016/j.ceb.2003.11.013

36. Tilley M, Fichera ME, Jerome ME, Roos DS, White MW. Toxoplasma gondii sporozoites form a transient parasitophorous vacuole that is impermeable and contains only a subset of dense-granule proteins. Infect Immun. (1997) 65:4598-605. doi: 10.1128/IAI.65.11.4598-4605.1997

37. Wang XC, Gong PT, Zhang X, Li S, Lu XY, Zhao CY, et al. NLRP3 inflammasome participates in host response to Neospora caninum infection. Front Immunol. (2018) 1791:9. doi: 10.3389/fimmu.2018.01791

38. Dong JQ, Li JH, Wang JP, Li F, Yang J, Gong PT, et al. Identification and characterization of GRA6/ GRA7 of Neospora caninum in MDBK cells. Acta Bioch Bioph Sin. (2017) 49:361-6. doi: 10.1093/abbs/gmx01

39. Coppens I, Dunn JD, Romano JD, Pypaert M, Zhang H, Boothroyd JC, et al. Toxoplasma gondii sequesters lysosomes from mammalian hosts in the vacuolar space. Cell. (2006) 125:261-74. doi: 10.1016/j.cell.2006.01.056

40. Cesbron-Delauw MF, Gendrin C, Travier L, Ruffiot P, Mercier C. Apicomplexa in mammalian cells: trafficking to the parasitophorous vacuole. Traffic. (2008) 9:657-64. doi: 10.1111/j.1600-0854.2008.00728.x

41. Romano JD, Nolan SJ, Porter C, Ehrenman K, Hartman EJ, Hsia R, et al. The parasite Toxoplasma sequesters diverse Rab host vesicles within an intravacuolar network. J Cell Biol. (2017) 216:4235-54. doi: 10.1083/jcb.201701108

42. Gendrin C, Bittame A, Mercier C, Cesbron-Delauw MF. Post-translational membrane sorting of the Toxoplasma gondii GRA6 protein into the parasite-containing vacuole is driven by its $\mathrm{N}$-terminal domain. Int J Parasitol. (2010) 40:1325-34, doi: 10.1016/j.ijpara.2010.03.014

43. Manghwar H, Lindsey K, Zhang XL, Jin SX. CRISPR/Cas system: recent advances and future prospects for genome editing. Trends Plant Sci. (2019) 24:1102-25. doi: 10.1016/j.tplants.2019.09.006

44. Doudna JA, Charpentier E. Genome editing. The new frontier of genome engineering with CRISPR-Cas9. Science. (2014) 346:1258096. doi: 10.1126/science. 1258096

45. Mali P, Esvelt KM, Church GM. Cas9 as a versatile tool for engineering biology. Nat Methods. (2013) 10:957-63. doi: 10.1038/nmeth.2649

46. Bartova E, Sedlak K. Toxoplasma gondii and Neospora caninum antibodies in goats in the Czech Republic. Vet. Med-czech. (2018) 57:111-4. doi: 10.17221/5850-VETMED

47. Lukášová R, Kobédová K, Halajian A. Molecular detection of Toxoplasma gondii and Neospora caninum in birds from South Africa. Acta Trop. (2018) 178:93-8. doi: 10.1016/j.actatropica.2017.10.029

48. Moskwa B, Kornacka A, Cybulska A, Cabaj W, Reiterova K, Bogdaszewski M, et al. Seroprevalence of Toxoplasma gondii and Neospora caninum infection in sheep, goats and fallow deer farmed on the same area. J. Anim. Sci. (2018) 96:2468-73. doi: 10.1093/jas/sky122

49. Wong A, Lanyon JM, O'Handley R, Linedale R, Woolford L, Long T, et al. Serum antibodies against Toxoplasma gondii and Neospora caninum in southeast Queensland dugongs. Mar Mammal Sci. (2019) 36:18094. doi: 10.1111/mms.12629

50. Arranz-Solís D, Regidor-Cerrillo J, Lourido S, Ortega-Mora LM, Saeij JPJ. Toxoplasma CRISPR/Cas9 constructs are functional for gene disruption in Neospora caninum. Int J Parasitol. (2018) 48:597-600. doi: 10.1016/j.ijpara.2018.03.002

51. Shen B, Brown KM, Lee TD, Sibley LD. Efficient gene disruption in diverse strains of Toxoplasma gondii using CRISPR/CAS9. mBio. (2014) 5:e0111414. doi: $10.1128 / \mathrm{mBio} .01114-14$

52. Yang C S, Liu J, Ma L, Zhang XC, Zhang X, Zhou BX, et al. NcGRA17 is an important regulator of parasitophorous vacuole morphology and pathogenicity of Neospora caninum. Vet Parasitol. (2018) 264:2634. doi: 10.1016/j.vetpar.2018.03.018

53. Ghorbal M, Gorman M, Macpherson CR, Martins RM, Scherf A, LopezRubio JJ. Genome editing in the human malaria parasite Plasmodium falciparum using the CRISPR-Cas9 system. Nat Biotechnol. (2014) 32:81921. doi: $10.1038 /$ nbt. 2925

54. Peng D, Kurup SP, Yao PY, Minning TA, Tarleton RL. CRISPR-Cas9-mediated single-gene and gene family disruption in Trypanosoma cruzi. mBio. (2014) 6:e2097-14. doi: 10.1128/mBio.02097-14

55. Sollelis L, Ghorbal M, MacPherson CR, Martins RM, Kuk N, Crobu $\mathrm{L}$, et al. First efficient CRISPR-Cas9-mediated genome editing in Leishmania parasites. Cell Microbiol. (2015) 17:1405-12. doi: 10.1111/cmi. 12456

56. Wagner JC, Platt RJ, Goldfless SJ, Zhang F, Niles JC. Efficient CRISPR-Cas9mediated genome editing in Plasmodium falciparum. Nat Methods. (2014) 11:915-8. doi: 10.1038/nmeth.3063

57. Zhang WW, Matlashewski G. CRISPR-Cas9-mediated genome editing in Leishmania donovani. mBio. (2015) 6:e00861. doi: 10.1128/mBio.00861-15

Conflict of Interest: The authors declare that the research was conducted in the absence of any commercial or financial relationships that could be construed as a potential conflict of interest.

Copyright (c) 2021 Dong, Zhang, Zhao, Li, Cao, Wang, Li, Yang, Zhang and Gong. This is an open-access article distributed under the terms of the Creative Commons Attribution License (CC BY). The use, distribution or reproduction in other forums is permitted, provided the original author(s) and the copyright owner(s) are credited and that the original publication in this journal is cited, in accordance with accepted academic practice. No use, distribution or reproduction is permitted which does not comply with these terms. 